\title{
Limitations of Inlet Air Evaporative Cooling System for Enhancing Gas Turbine Performance in Hot and Humid Climates
}

\author{
Majed Alhazmy ${ }^{1}$, Badr Habeebullah ${ }^{1}$, Rahim Jassim ${ }^{2}$ \\ ${ }^{1}$ Mechanical Engineering, King Abdulaziz University, Jeddah, Kingdom of Saudi Arabia \\ ${ }^{2}$ Saudi Electric Services Polytechnic (SESP), Baish, Jazan Province, Kingdom of Saudi Arabia
}

Email address:

bhabeeb@kau.edu.sa (B. Habeebullah),mhazmy@kau.edu.sa (M. Alhazmy), rkjassim@yahoo.com (R. Jassim)

\section{To cite this article:}

Majed Alhazmy, Badr Habeebullah, Rahim Jassim. Limitations of Inlet Air Evaporative Cooling System for Enhancing Gas Turbine Performance in Hot and Humid Climates. International Journal of Energy and Power Engineering. Vol. 4, No. 5, 2015 , pp. $287-297$. doi: $10.11648 /$ j.ijepe.20150405.18

\begin{abstract}
This paper aims to investigate the evaporative cooling limitations of compressor intake-air for improving the performance of gas turbine power plants. The limitations of the evaporative cooling capability are analyzed and formulated in terms of the characteristic dimensions involving the temperature ratio, the power gain ratio (PGR), thermal efficiency change, and humidity ratio. The effects of different pressure ratios (PRs) are examined for Saudi Arabia summer weather when the turbine inlet temperature is predetermined at1373.15 K. The results of a specific example where the air evaporative cooler drops the temperature to the wet bulb temperature are presented. These indicate that the power gain ratio enhancement depends on the ambient temperature, relative humidity, evaporative cooler effectiveness, and slightly the PR. Especially for PR $=10$, the PGR is enhanced by $9 \%$ at $20 \%$ of relative humidity and dropped to $3.37 \%$ at $60 \%$ of relative humidity. The daily performance of the evaporative cooling method is examined for the hot humid conditions of Jeddah, Saudi Arabia. The results show that the evaporative cooler increased both the daily power output and the thermal efficiency by $2.52 \%$ and $0.112 \%$, respectively.
\end{abstract}

Keywords: Gas Turbine, Air-Cooling, Power Enhancement, Evaporative Cooler

\section{Introduction}

The electric power generation sectors in many countries face two real problems which are the continuous increase in fuel prices and the incessant growth in energy demand. In order to fulfill this demand and reduce the operation cost, improving the performance of their generation units is of necessity. Nowadays, gas turbine (GT) power plants are generation units being widely used in several countries all over the world due to their low cost, quick installation, and stability of electricity grid variations. Many of these countries obviously have a wide range of climatic conditions which negatively impact the GT performance. In hot climate countries, GT power output significantly falls more in summer due to the temperature rise. At the same time, high temperature would lead to the increase in electricity demand for air conditioning. For such challenge, several attempts have been carried out to improve the GT power output as well as thermal efficiency. According to Zadpoor [1], power augmentation can be classified into two main categories. The first category includes inlet air cooling techniques and the second involves techniques based on the injection of compressed air, steam, or water. Furthermore, a little increment of thermal efficiency could result in a significant amount of fuel being saved and a higher level of power being generated. The simplest remedy for this increment is to reduce the temperature of the inlet air. This is a reason why cooling the compressor intake air has obtained much consideration of utilities and is also a research subject in this paper.

Several methods have been using for cooling the GT intake air in which evaporation of water is one of the simplest and oldest methods. Even then the sophisticated technology available today such as mechanical compression chiller, absorption chiller, and thermal energy storage system, evaporating cooling remains the most cost-efficient method for temperature control of the gas turbine inlet air supply [2].Evaporative cooling can be achieved by many methods. In practical, two forms called direct methods involving media type evaporative cooling and spray type evaporative cooling 
are typically used [3].Many literature works have intensively investigated the compressor intake air cooling effect on the GT power enhancement. Johnson[4] discussed the use of evaporative cooling technique for GT installations. The calculation procedure and installation as well as operation details were also presented in his study. Ameriet al[5] applied a fog type air cooling system where fog nozzles inject water at high pressures (above 70 bars) generating micro fine droplets with sizes between 10 and 40 microns. Performance test results showed that the power output of the units has increased by $13 \%$ of the generated power, while the efficiency improvement was less than $1 \%$. Since operation of the nozzles is critical to the fogging system, Meheret al[6] investigated the effect of nozzles type and droplets size on the performance of GT engines. Typically, the nozzles were stainless steel-316 of diameters less than $0.18 \mathrm{~mm}$ diameter. Because of the limited size of droplets produced by these nozzles (greater than 4 microns), humid air cannot exceed 90 to $95 \%$ of the saturation relative humidity [7-8]. Retrofitting of evaporative air coolers usually requires large ducts as the evaporation process requires low velocities. If the air velocity is high, water carry over may affect the compressor blades. For these reasons, use of evaporative cooling is limited and works better in dry air locations. Other investigations confirm the advantages of air cooling in which the most recent study is the study of Alhazmy and Najjar [5].They examined the power output and net efficiency of GT by using direct water spray process and surface cooling coils at the inlet of the compressor. For spray cooler, the drop in air temperature is $3-15^{\circ} \mathrm{C}$ resulting in the increase of the power output from 1 to $7 \%$. In case of water scarcity, they suggested the use of the condensate from the waste gases to recover partially for the spray water.

Generally, the evaporative methods for cooling the compressor intake air are diverse. Each of these methods has its advantages as well as limits. In this study, an evaporative air cooler is considered and analyzed to ascertain its limitation cooling process, the capability of boosting the power output, and the thermal efficiency enhancement of GT operating for long periods in a hot and humid climate. The performance of the cooling system is then presented in a dimensionless graph where the power gain and thermal efficiency enhancement can be effortlessly evaluated for different ambient conditions and evaporative cooler effectiveness.

\section{Description of Analysis}

In this study, a simple open type gas turbine cycle as shown in Fig. 1 is considered. The cycle performance can be improved by cooling the compressor intake air using a direct evaporative air-cooling system. The cooling is achieved by evaporation of water spray in an evaporative cooler installed ahead of the compressor inlet manifolds. The ambient air enters the cooler at state 0 and comes in the compressor at state 1.

\subsection{Gas Turbine Cycle Analysis}

Consider an irreversible gas turbine cycle as shown in Fig. 2; processes 1-2 and 3-4 are irreversible while processes 2-3 and 4-1 are isobaric heat addition and rejection, respectively. Processes $1-2 \mathrm{~s}$ and $3-4 \mathrm{~s}$ are isentropic presenting the process in an ideal cycle.

For the isentropic processes $1-2 \mathrm{~s}$ and $3-4 \mathrm{~s}$, we have

$$
\frac{T_{2 s}}{T_{1}}=\frac{T_{3}}{T_{4 s}}=\left[\frac{P_{2}}{P_{1}}\right]^{\frac{k-1}{k}}=P R^{\frac{k-1}{k}}
$$

where $P R$ is the pressure ratio and $k$ is the specific heats ratio.

\subsubsection{Turbine}

If a cooling system extracts its power from the turbine output as shown in Fig. 1, the thermal efficiency of the cycle is

$$
\eta_{c y}=\frac{\dot{W}_{n e t}}{\dot{Q}_{h}}=\frac{\dot{W}_{t}-\left(\dot{W}_{\text {comp }_{\text {air }}}+\dot{W}_{\text {el, pump }}\right)}{\dot{Q}_{h}}
$$

where $\dot{W}_{e l, p u m p}$ is the pumping power to circulate the water inside the evaporative cooler.

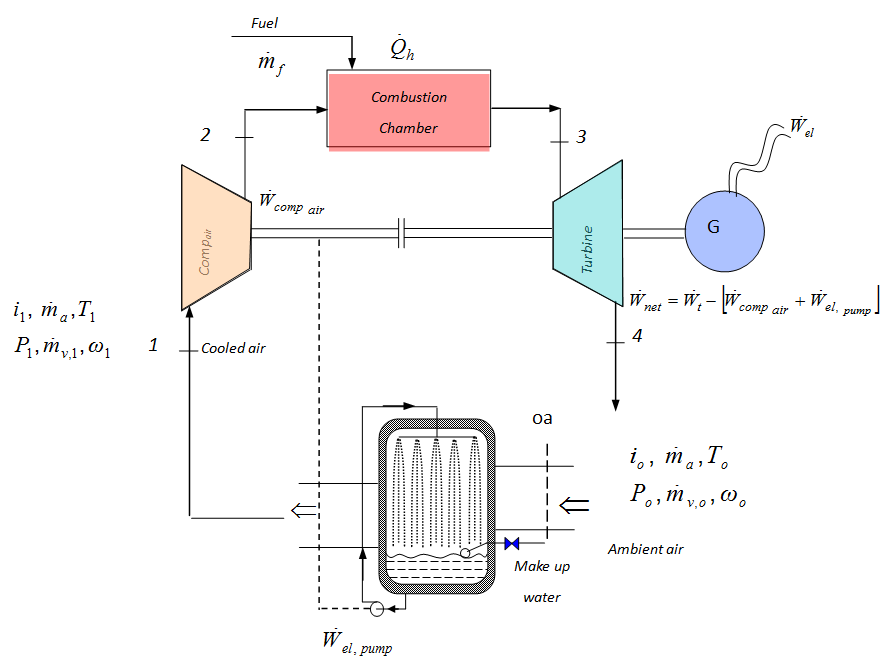

Fig. 1. A simple open type gas turbine with a direct evaporative cooler. 


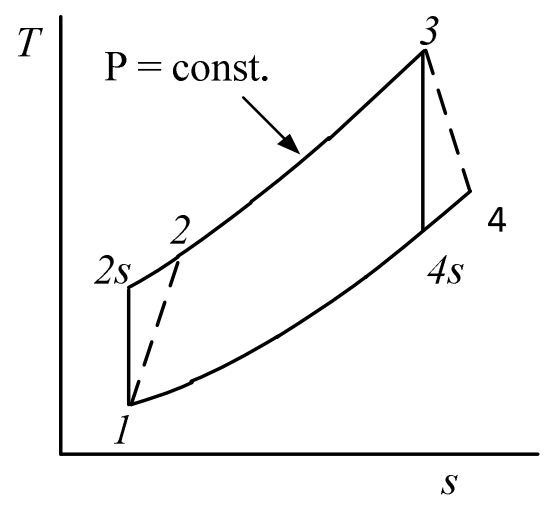

Fig. 2. T-S diagram of an open type gas turbine cycle.

Applying the first law of thermodynamics to the gas turbine (neglect the potential and kinetic energy terms), the power produced by the turbine is

$$
\dot{W}_{t}=\dot{m}_{t} c_{p g} \eta_{t}\left(T_{3}-T_{4 s}\right)
$$

where $\omega_{1}$ is the humidity ratio at state $1, f=\dot{m}_{f} / \dot{m}_{a}$ is the fuel air ratio, and $\dot{m}_{t}$ is the total gases mass flow rate at the turbine inlet given as

$$
\dot{m}_{t}=\dot{m}_{a}+\dot{m}_{v}+\dot{m}_{f}=\dot{m}_{a}\left(1+\omega_{1}+f\right)
$$

Substituting for $T_{4 s}$ and $\dot{m}_{t}$ from Eqs. 1 and 4 into Eq. 3 yields

$$
\dot{W}_{t}=\dot{m}_{a}\left(1+\omega_{1}+f\right) c_{p g} \eta_{t} T_{3}\left(1-\frac{1}{P R^{\frac{k-1}{k}}}\right)
$$

The turbine isentropic efficiency can be estimated by using the practical relations recommended by Korakianitis and Wilson [9] as

$$
\eta_{t}=1-\left(0.03+\frac{P R-1}{180}\right)
$$

The gas turbine is almost constant volume machine at a specific rotating speed; hence, the inlet air volumetric flow rate $\dot{V}_{a}$ is fixed regardless of the ambient air conditions. As the air temperature rises in hot summer days, its density falls but the volumetric flow rate remains constant. Therefore, the mass flow rate reduces and consequently the power output decreases [5]. Eq.5 can be written in terms of the volumetric flow rate at the compressor inlet state as

$$
\dot{W}_{t}=\dot{V}_{a} \rho_{a}\left(1+\omega_{1}+f\right) c_{p g} \eta_{t} T_{3}\left(1-\frac{1}{P R^{\frac{k-1}{k}}}\right)
$$

where $\rho_{a}$ is the moist air density which is a function of the temperature $T_{1}$. The humidity ratio $\omega_{1}$ can be calculated by using the Engineering Equation Solver (EES) software[10]. The effect of the air pressure drop across chilling coils is small and can be neglected; hence, $P_{1} \cong P_{0}$. The air density will vary significantly with humidity ratio change from $\omega_{0}$ to $\omega_{1}$ and decrease in the air temperature from $T_{0}$ to $T_{1}$.

\subsubsection{Air Compressor}

For humid air, the compression power can be estimated from

$$
\dot{W}_{\text {compair }}=\dot{m}_{a} c_{p a}\left(T_{2}-T_{1}\right)+\dot{m}_{v}\left(i_{g 2}-i_{g 1}\right)
$$

where $i_{g 2}$ and $i_{g 1}$ are, respectively, the enthalpies of saturated water vapor at the compressor exit and inlet states; $\dot{m}_{v}=\dot{m}_{a} \omega_{1}$ is the mass of water vapor.

Relating the compressor isentropic efficiency to the changes in temperature of the dry air and assuming that the compression of water vapor behaves as an ideal gas,

$$
\eta_{c}=\frac{T_{2 s}-T_{1}}{T_{2}-T_{1}}
$$

from which $T_{2}$ is expressed in terms of $T_{1}$ and the pressure ratio $P R$ as

$$
T_{2}=T_{1}\left[\frac{P R^{\frac{k-1}{k}}-1}{\eta_{c}}+1\right]
$$

Substituting for $T_{2}$ into Eq. 8 gives the actual compressor power as

$$
\dot{W}_{\text {compair }}=\dot{m}_{a}\left[c_{p a} \frac{T_{1}}{\eta_{c}}\left(P R^{\frac{k-1}{k}}-1\right)+\omega_{1}\left(i_{g 2}-i_{g 1}\right)\right]
$$

where $\eta_{c}$ can be evaluated using the following empirical relation[9]:

$$
\eta_{c}=1-\left(0.04+\frac{P R-1}{150}\right)
$$

\subsubsection{Combustion Chamber}

Heat balance on the combustion chamber (as shown in Fig. 1) gives the heat rate supplied to the GT cycle as

$$
\dot{Q}_{h}=\dot{m}_{f} N C V=\left(\dot{m}_{a}+\dot{m}_{f}\right) c_{p g} T_{3}-\dot{m}_{a} c_{p a} T_{2}+\dot{m}_{v}\left(i_{v 3}-i_{v 2}\right)
$$

Introducing the fuel air ratio $f=\dot{m}_{f} / \dot{m}_{a}$ and substituting for $T_{2}$ in terms of $T_{1}$ from Eq. 10 give the cycle heat rate as 


$$
\dot{Q}_{h}=\dot{m}_{a} T_{1}\left[(1+f) c_{p g} \frac{T_{3}}{T_{1}}-c_{p a}\left(\frac{P R^{\frac{k-1}{k}}-1}{\eta_{c}}+1\right)+\frac{\omega_{1}}{T_{1}}\left(i_{v 3}-i_{v 2}\right)\right]
$$

where $f$, as expressed in [5], is

$$
f=\frac{c_{p g}\left(T_{3}-298\right)-c_{p a}\left(T_{2}-298\right)+\omega_{1}\left(i_{v 3}-i_{v 2}\right)}{N C V-c_{p g}\left(T_{3}-298\right)}
$$

$i_{v 2}$ and $i_{v 3}$ are the enthalpies of water vapor at the combustion chamber inlet and exit states, respectively. They can be calculated from [11]

$$
i_{v, j}=2501.3+1.8723 T_{j} ; j=2 \text { or } 3
$$

It is seen that the three terms of the gas turbine efficiency in Eq. $2\left(\dot{W}_{t}, \dot{W}_{\text {comp,air }}\right.$, and $\left.\dot{Q}_{h}\right)$ depend on the air temperature and relative humidity at the compressor inlet whose values are affected by the type and performance of the cooling system.

\subsection{Evaporative Water Spray Process}

In evaporative cooling, water and intake air are brought into direct contact where the warm air stream transfers heat to sprayed water as shown in Fig. 3a. During the air-water heat exchange process, part of the liquid water evaporates causing the temperature of the air to decrease adiabatically, presented as line $0-1$ in Fig. 3b. The air humidity ratio increases from $\omega_{0}$ to $\omega_{1}$ approaching the saturation condition. As the air approaches the saturation limit, the evaporation process takes more time where the air cannot carry more water and further water injection is not utilized. Therefore, the evaporative cooling of air is limited by the temperature difference $\left(T_{0}-T_{1}\right)$. In practice, cooling the air to the saturation state requires water over spraying that may initiate the carryover of droplets, which causes fouling of compressor blades and/or rust of the entrance ducts. Controlling the parameters of evaporative coolers is an important key to the successful seasonal operation of coolers. The effectiveness of an evaporative air-cooler $\left(\varepsilon_{e v c}\right)$ is defined as the ratio between the actual dry bulb temperature decreases and the theoretical temperature difference if the air leaves the cooler at saturation state. Typical evaporative cooler effectiveness range is from 0.8 to 0.9 [12].
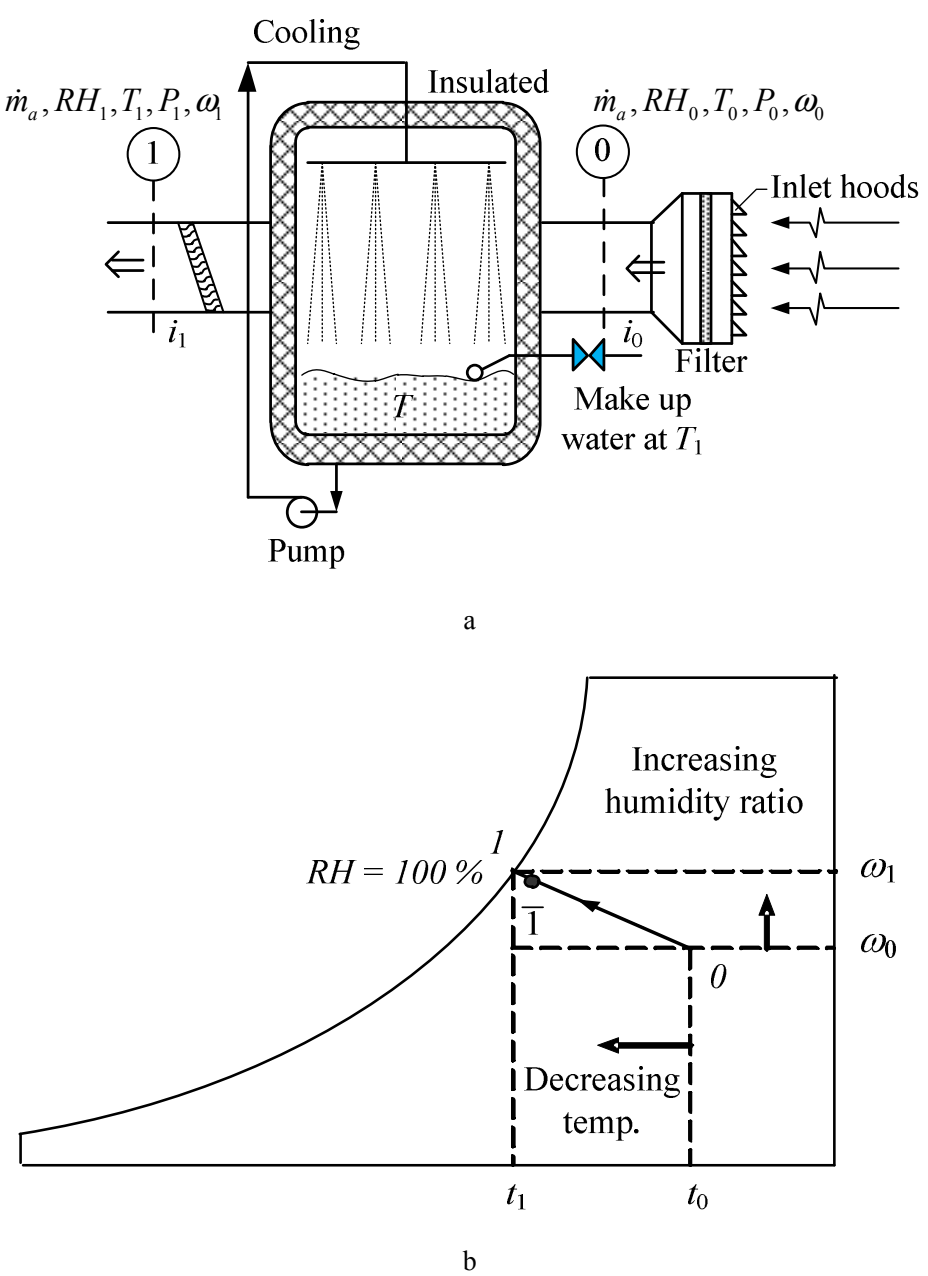

Fig. 3. (a Schematic of adiabatic evaporative cooler; b) adiabatic saturation process on the psychometric chart. 
Fig. 3a shows a schematic of an evaporative cooler where the ambient air at $T_{0}, \omega_{0}$, and $P_{0}$ enters the spray chamber and leaves at $T_{1}, \omega_{1}$, and $P_{1}$. The evaporative cooler is assumed to operate in a steady adiabatic process such that the ambient moist air enters at $T_{0}$ and $\mathrm{RH}_{0}$ and leaves at state 1 . Adequate quantity of water is added to the air stream to raise its moisture content close to $100 \%$ relative humidity and decrease its temperature as shown in Fig. 3b. Applying energy balance yields [13]

$$
\omega_{o}\left(i_{v o}-i_{w}\right)=c_{p a}\left(T_{1}-T_{o}\right)+\omega_{1}\left(i_{f g 1}\right)
$$

where $i_{v o}$ and $i_{w}$ are saturated water vapor enthalpy at $T_{0}$ and saturated water liquid enthalpy at $T_{1}, i_{f g 1}$ is the latent heat of vaporization at state 1 , and $\omega_{0}$ is evaluated at the ambient conditions by using EES software.

\section{Gas Turbine Coupled to an Evaporative Spray Cooler}

In order to evaluate the feasibility of a cooling system coupled to a GT plant, the performance of the plant is examined with and without the cooling system. In general, the net power output of a complete system is

$$
\dot{W}_{n e t}=\dot{W}_{t}-\left(\dot{W}_{\text {comp }_{\text {air }}}+\dot{W}_{e l, p u m p}\right)
$$

The three terms of Eq. 18 are functions of the air properties at the compressor intake $\left(T_{1}\right.$ and $\left.\omega_{1}\right)$, which in turn depends on the performance of the cooling system. A dimensionless term that gives the advantage of using any cooling system as the power gain ratio (PGR) is defined:

$$
P G R=\frac{\dot{W}_{\text {net, with cooling }}-\dot{W}_{\text {net, without cooling }}}{\dot{W}_{\text {net, without cooling }}} \times 100 \%
$$

The PGR is a generic term that takes into account all the parameters of the GT and the associated cooling system irrespective of the cooling process. For a stand-alone GT under specific climatic conditions, PGR is equal to 0 . If a cooling system is used, the PGR increases with the reduction of the intake temperature; but this increase is restricted by the physical limits of the cooling process. However, the PGR gives the percentage enhancement in power generation and the thermal efficiency of a coupled system, which is an important parameter to describe the input/output relation. Another factor that physically relates to the thermal efficiency of a stand-alone GT to that coupled cooling system as the thermal efficiency change (TEC) is given:

$$
T E C=\frac{\eta_{c y, \text { with cooling }}-\eta_{c y, \text { without cooling }}}{\eta_{c y, \text { without cooling }}} \times 100 \%
$$

However, the PGR is always positive whilst TEC can be negative, which means that the efficiency of the coupled system is less than that of a stand-alone GT even at low intake temperatures. Both PGR and TEC provide dimensionless parameters that can be easily employed and interpreted.

For evaporative cooling, the power consumed by the cooling system $\dot{W}_{\text {el,pump }}$ is the pumping power to circulate the water inside the chamber (as shown in Fig. 3a). This power is small compared to the other terms in Eq.18 and can be ignored. Therefore, the PGR for a gas turbine with evaporative cooler can be obtained by substituting Eqs.5, 11, and 18 into Eq.19. From Eqs. 2,5,11, and 18, the cycle thermal efficiency with cooling $\eta \mathrm{cy}, \mathrm{evc}$ in terms of the air properties at the compressor intake and the fuel air ratio can be expressed as

$$
\eta_{c y, e v c}=\frac{\left(1+\omega_{1}+f\right) c_{p g} \eta_{t} \frac{T_{3}}{T_{1}}\left(1-\frac{1}{P R^{\frac{k-1}{k}}}\right)-\left[c_{p a} \frac{1}{\eta_{c}}\left(P R^{\frac{k-1}{k}}-1\right)+\frac{\omega_{1}}{T_{1}}\left(i_{g 2}-i_{g 1}\right)\right]}{(1+f) c_{p g} \frac{T_{3}}{T_{1}}-c_{p a}\left(\frac{P R^{\frac{k-1}{k}}-1}{\eta_{c}}+1\right)+\frac{\omega_{1}}{T_{1}}\left(i_{v 3}-i_{v 2}\right)}
$$

Eq.21 for an ideal air reversible cycle when $\eta_{c}=\eta_{t}=1$, fuel air ratio $f=0, c_{p g}=c_{p a}$, and the inlet air humidity ratio $\omega_{1}=0$ gives the standard expression in which the pressure ratio is the only dependent $\left(\eta_{c y, r e v}=1-1 / P R^{(k-1) / k}\right)$. For a stand-alone (without cooling) GT the third term of the nominator vanishes and the inlet conditions $T_{1}$ and $\omega_{1}$ are replaced by $T_{0}$ and $\omega_{0}$.

\section{Results and Discussion}

In order to investigate the performance of the direct evaporative cooling method on the GT power output and thermal efficiency, a computer program has been developed to calculate the PGR and TEC for different operation conditions. The thermo physical properties were determined to obtain the accuracy from the EES software. In particular, the specific heats of air and combustion gases are both temperature dependent. Table 1 shows the range of the different operating parameters for this analysis.

The selected maximum air temperature $t_{o \text {, } \max }$ which was close to $50^{\circ} \mathrm{C}$ is based on meteorological data recorded during the past few years in Saudi Arabia. An average design value of $44.5 \%$ for the relative humidity is selected as base data. For 
fixed values of $T_{3}, T_{o}$, and $R H_{o}$, the assumption is that the maximum cooling can be achieved if the air is cooled to the wet bulb temperature and the pumping power $\dot{W}_{\text {el,pump }}$ is neglected.

Table 1. Range of parameters.

\begin{tabular}{lll}
\hline Component & Parameter & Range \\
\hline \multirow{3}{*}{ Ambient air } & Max. ambient air temperature $T_{0, \max }$ & $323.15 \mathrm{~K}$ \\
& Relative humidity $R H_{0}$ & From $0 \%$ to $100 \%$ \\
& Volumetric air flow rate & $1 \mathrm{~m}^{3} / \mathrm{s}$ \\
& Pressure ratio $P_{2} / P_{1}$ & 10 \\
Gas turbine & Turbine inlet temperature $T_{3}$ & $323.15 \mathrm{~K}$ \\
& Turbine efficiency $\eta_{t}($ Eq.6) & From 0.91 to 0.93 \\
& Air compressor efficiency $\eta_{t}($ Eq. 12$)$ & From 0.88 to 0.91 \\
\hline
\end{tabular}

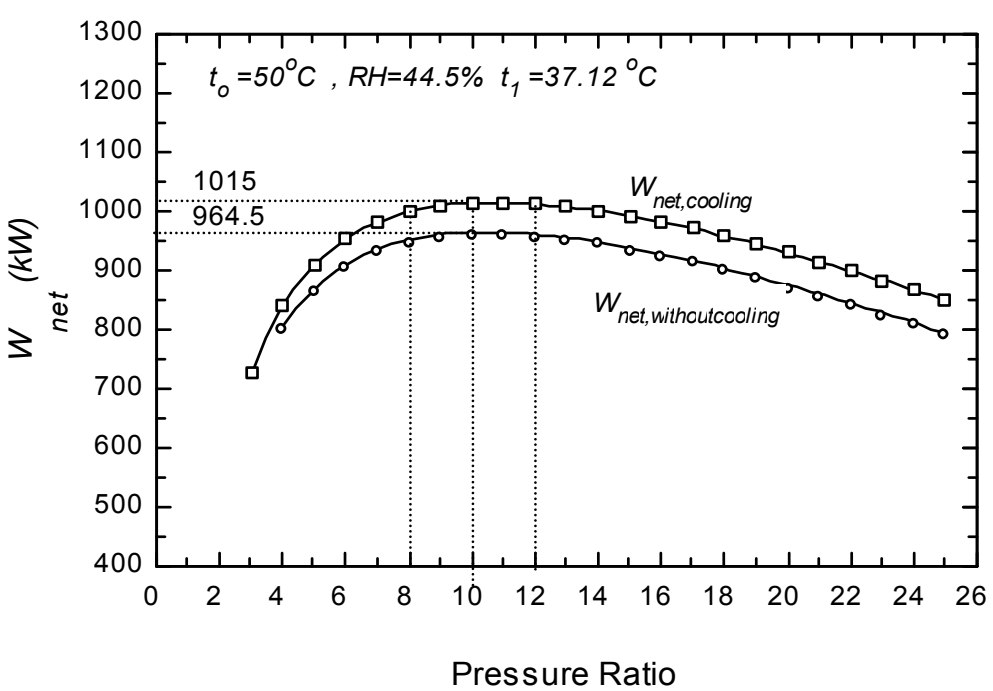

Fig. 4. Dependence of net work on the pressure ratio.

Fig. 4 shows the network is a function of PR. It can be seen that the net gas turbine power output increases together with the PR increase until it reaches a maximum at $\mathrm{PR}=10$. Afterwards, the power slowly declines. The same trend is observed for the gas turbine when coupled to a cooling system. Increasing the PR causes the increase in both the turbine and compressor powers at different rates. The maximum power occurs at a PR where the rate of increase in the turbine power is greater than that required to drive the air compressor. For larger values of PR, the net work tends to decrease as a result of the percentage increase in power required to drive the air compressor as shown in Fig. 5. This figure also shows that the net output power can achieve the maximum value when the PR approximately falls into the range from 8 to 12 .

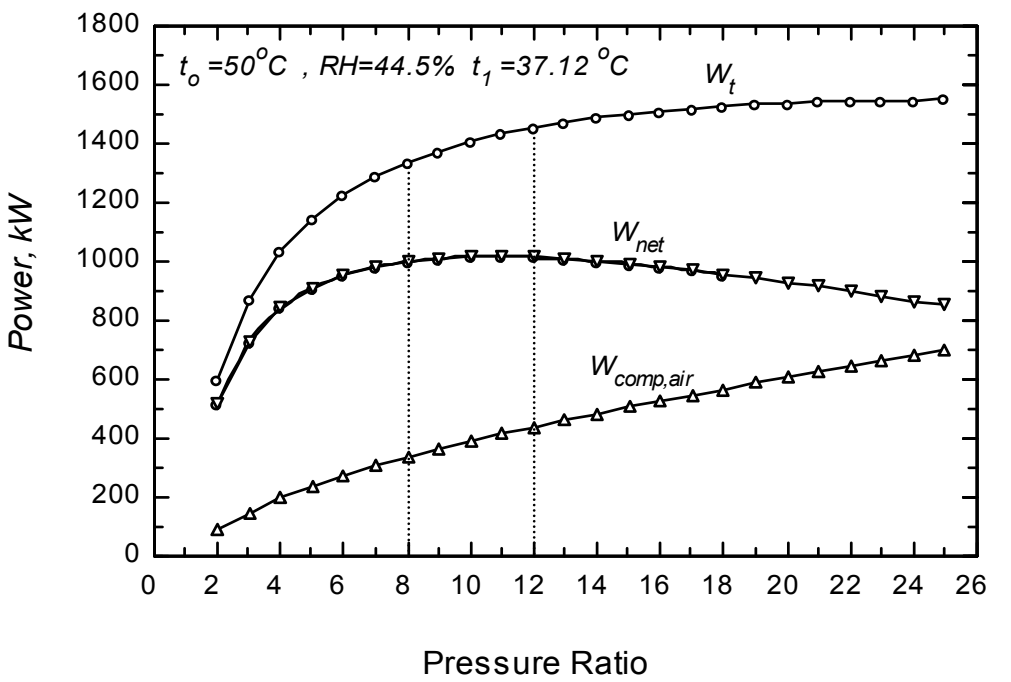

Fig. 5. The power for a gas turbine system using a direct evaporative cooler. 


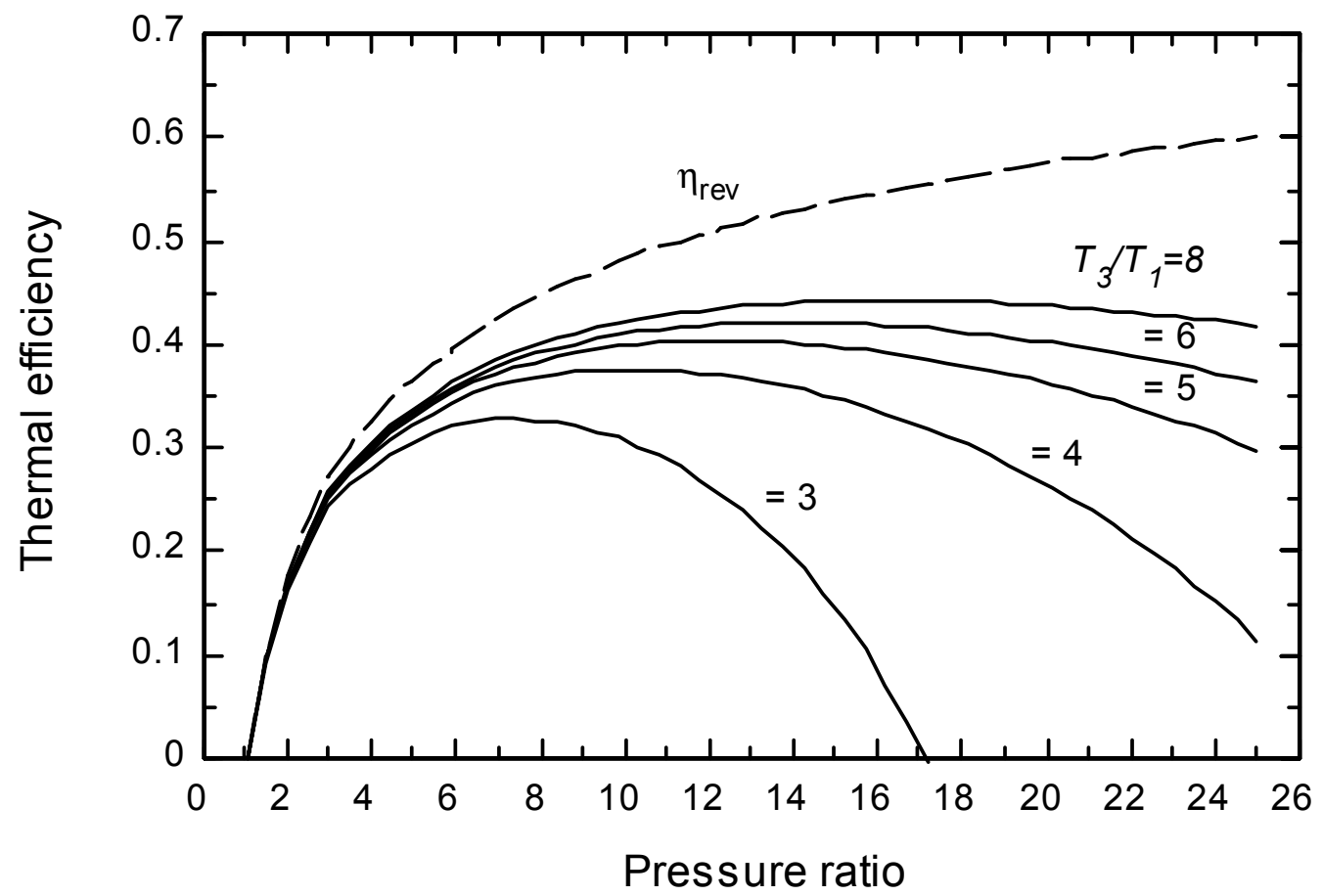

Fig. 6. The thermal efficiency of a simple gas turbine cycle.

Fig. 6 shows the thermal efficiency variation according to the PR for different turbine inlet absolute temperature. As the maximum temperature $T_{3}$ is kept constant $(1373.15 \mathrm{~K})$, an increase in the PR will increase the cycle efficiency. However, the PR is limited and will reach the maximum when the air temperature at the compressor outlet is equal to the design turbine inlet temperature. In this case, the cycle net work tends towards zero and the cycle efficiency approaches the reversible efficiency [14]. In this case study where the direct evaporative cooler is used to cool the outlet air temperature from $50^{\circ} \mathrm{C}$ to wet bulb temperature $\left(37.12^{\circ} \mathrm{C}\right)$, the term $T_{3} / T_{1}$ increases from 4.25 to 4.425 . Consequently, the thermal efficiency increases as shown by the trends in Fig. 6. Fig. 7 shows the thermal efficiency of the gas turbine is improved by $0.24 \%$ for evaporative cooling and it is of positive magnitude.

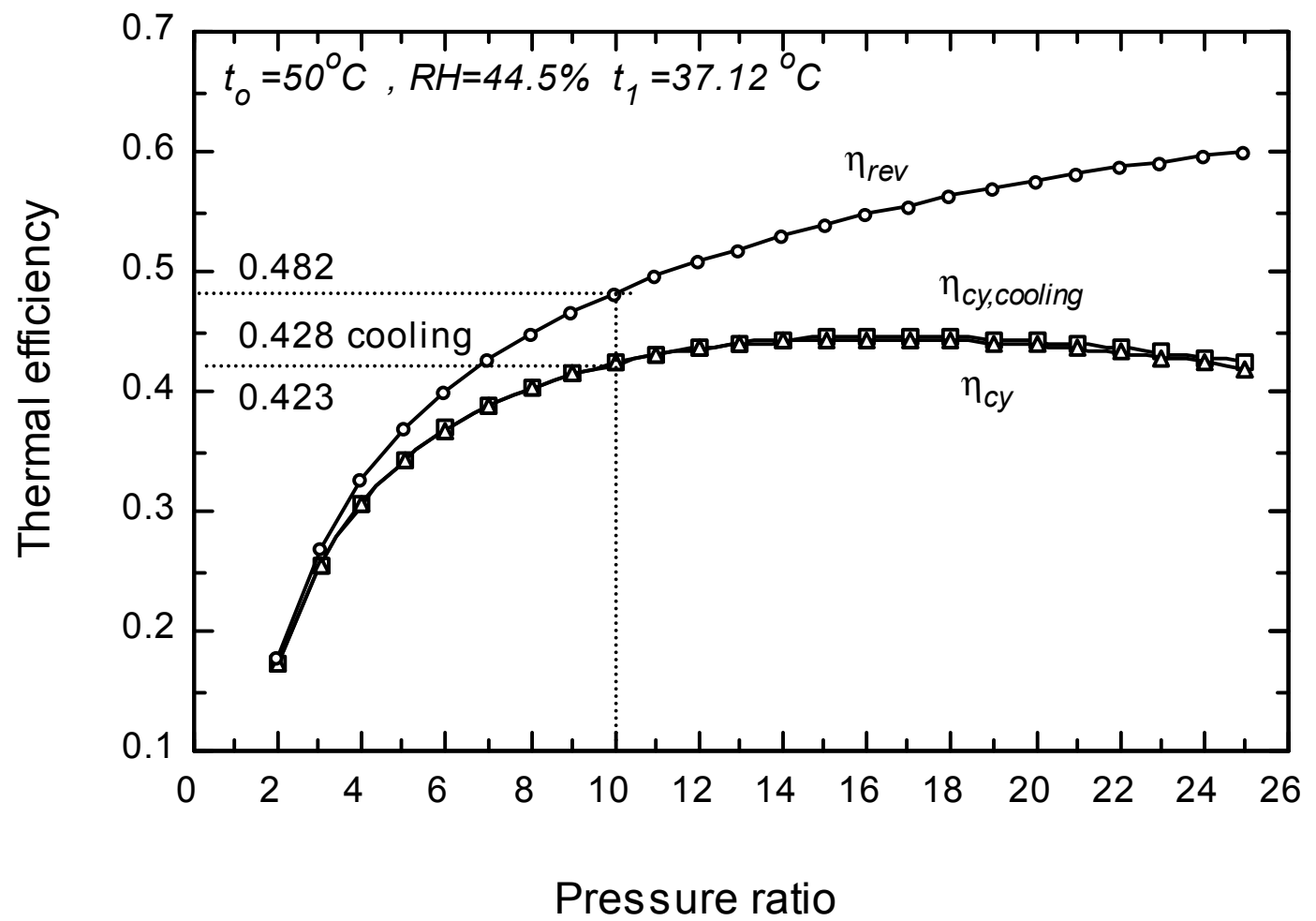

Fig. 7. Dependence of thermal efficiency on pressure ratio of a direct evaporative cooler. 


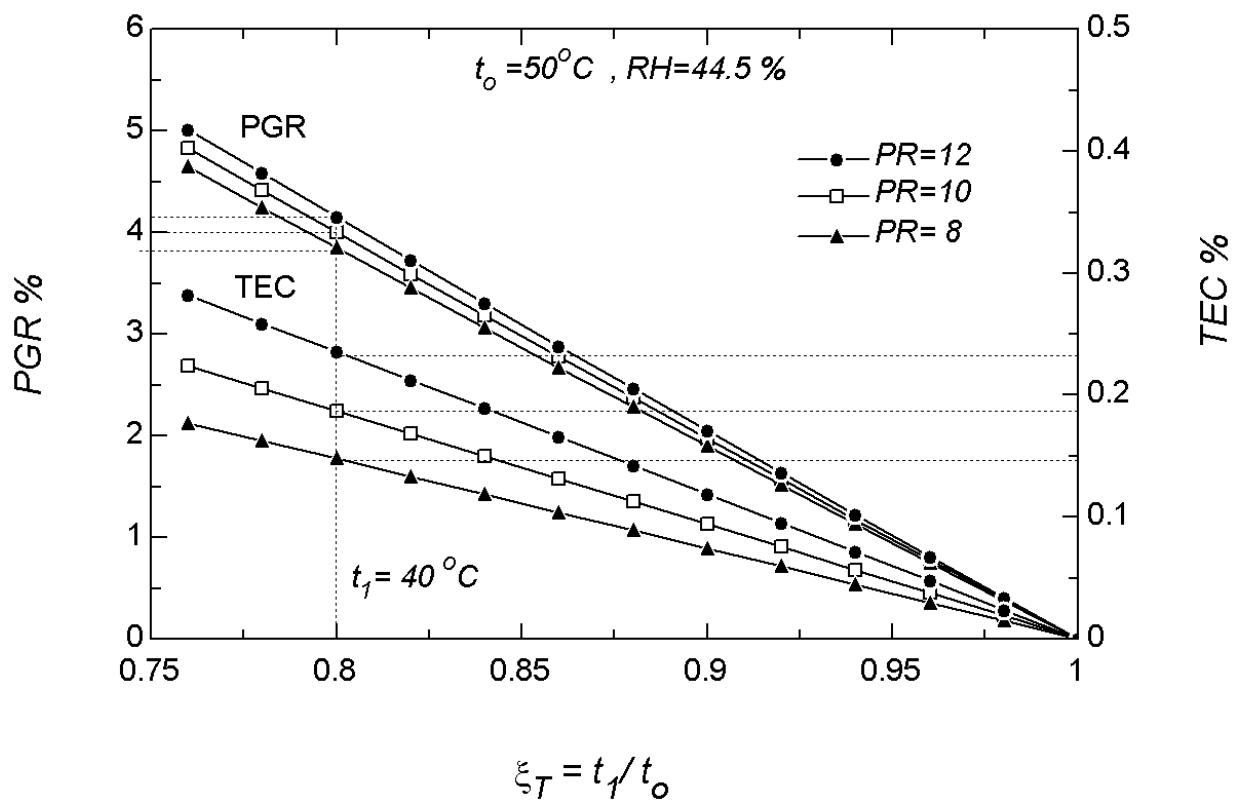

Fig. 8. Variation of the PGR, TEC, and the temperature ratio for a gas turbine with inlet air evaporative cooling.

By applying Eqs.19 and 20 for an evaporative air cooler system, the variation of the PGR and TEC with the temperature ratio $\xi_{T}=t_{1} / t_{o}$ is obtained and presented in Fig. 8. The factor $\xi_{T}$ presents physically the ratio between the air temperatures at the cooler exit and the ambient temperature in Celsius (cooling process attainment). For a constant PR (PR = $10)$, the PGR increases with decreasing of $\xi_{T}$ and a power gain factor of $4 \%$ can be obtained by cooling the air from $50^{\circ} \mathrm{C}$ to $40^{\circ} \mathrm{C}$.

The evaporative air cooler is designed to lower the ambient air temperature to a degree close to the ambient wet bulb temperature, which limits its cooling capability in humid climate areas. By applying Eqs.19, 20, and 21 with the assumption that $\dot{W}_{e l, p u m p}$ is zero, the PGR and TEC are computed for fixed ambient conditions as shown in Fig. 8. For temperature and relative humidity of $50^{\circ} \mathrm{C}$ and $44.5 \%$, respectively, the air temperature can be theoretically reduced in an adiabatic process to $37.12^{\circ} \mathrm{C}$ (wet bulb temperature) for which $\xi_{T}=0.74$. As shown in Fig. 8 at $\xi_{T}=0.74$ and PR of 10 , the power gain reaches $4.8 \%$ and the thermal efficiency change is $0.22 \%$. However, the value is small but substantiates an improvement in efficiency. This result shows that there is a gain in power and improvement in thermal efficiency. This advantage is soon offset by the fact that the system cannot provide any further improvement beyond the limiting state at specified ambient conditions.

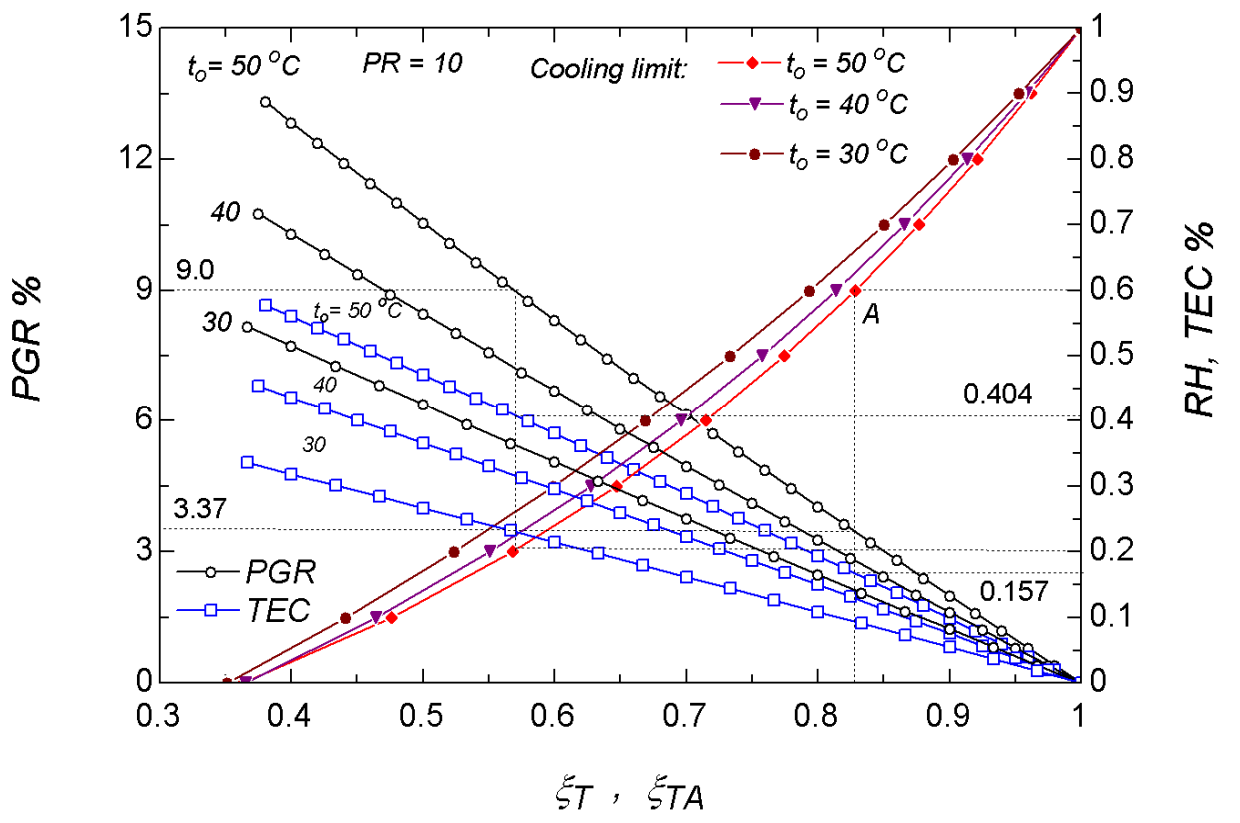

Fig. 9. The cooling limit of air evaporative cooler. 
Fig. 9 shows the PGR and TEC for different ambient air temperatures $\left(50^{\circ} \mathrm{C}, 40^{\circ} \mathrm{C}\right.$, and $\left.30^{\circ} \mathrm{C}\right)$ and the whole range of $\mathrm{RH}$ up to $100 \%$. The curves in the figure present the variation of the RH with $\xi_{T}$ at the maximum gain, which equals $t_{w b} / t_{o}$. Therefore, these curves determine the limiting condition for evaporative cooling once the ambient temperature and relative humidity are prescribed. For example, to determine the maximum power gain ratio and thermal efficiency change for ambient conditions of $50^{\circ} \mathrm{C}$ and $60 \% \mathrm{RH}_{0}$, first we draw a horizontal line from $60 \%$ relative humidity until it intersects the cooling limit of $t_{0}=50^{\circ} \mathrm{C}$ to obtain point $\mathrm{A}$ on the figure. At this point, $\xi_{T}$ determines the lowest air temperature at the compressor inlet; intersection with the lines of PGR and TEC (at $t_{0}=50^{\circ} \mathrm{C}$ ) gives the maximum values of the PGR and TEC as $3.37 \%$ and $0.157 \%$, respectively. Further, the results in Fig. 9 are presented for an ideal evaporative cooler effectiveness $\varepsilon_{e v c}=100 \% . \varepsilon_{e v c}$ can be computed as

$$
\varepsilon_{e v c}=\frac{t_{o}-t_{\overline{1}}}{t_{o}-t_{1}}=\frac{1-\xi_{T, A}}{1-\xi_{T}}
$$

exit to the ambient air temperature in Celsius and is equal to $t_{\overline{1}} / t_{o}$. From Eq.22, $\xi_{T, A}$ can be expressed as

$$
\xi_{T, A}=1-\varepsilon_{e v c}\left(1-\xi_{T}\right)
$$

To include the effectiveness $\varepsilon_{e v c}$ in the analysis, $\xi_{T}$ is replaced by $\xi_{T, A}$ and the PGF and TEC can be evaluated from Fig. 9. The effect of evaporative cooler effectiveness on both the PGR and TEC is shown in Table 2 for $\varepsilon_{e v c}=0.85$.

The relative humidity of ambient air is a key parameter for the evaporative cooler cooling capability. For illustration, we consider air at constant dry bulb temperature of $40^{\circ} \mathrm{C}$ and $60 \%$ $\mathrm{RH}_{0}$, for which the maximum PGR and TEC are $3.013 \%$ and $0.137 \%$, respectively. In the case $\xi_{T}=0.814$, the air temperature can only be reduced from $40^{\circ} \mathrm{C}$ to $32.56^{\circ} \mathrm{C}$. For an intermediate level of $40 \%$ humidity and the same dry bulb temperature, the corresponding temperature ratio $\xi_{T}$ is 0.696 , for which the temperature limit is $27.83^{\circ} \mathrm{C}$. The corresponding power gain is $5.012 \%$. The detailed results for the effect of the $\mathrm{RH}$ on the evaporative cooling capacity are summarized in Table 2, which shows a direct inverse proportionality.

where $\xi_{T, A}$ is the ratio of the actual air temperature at the cooler

\begin{tabular}{|c|c|c|c|c|c|c|c|c|c|}
\hline \multicolumn{2}{|c|}{ Ambient air conditions } & \multicolumn{3}{|c|}{ Evaporative cooler with $\varepsilon_{\text {evc }} 100 \%$} & \multicolumn{5}{|c|}{ Evaporative cooler with $\varepsilon_{\mathrm{evc}} 85 \%$} \\
\hline $\mathrm{t}_{0}\left({ }^{\circ} \mathrm{C}\right)$ & $R H_{o}(\%)$ & $\mathbf{t}_{1}\left({ }^{\circ} \mathrm{C}\right)$ & $\xi_{\mathrm{T}}$ & PGR (\%) & TEC (\%) & $t_{\overline{1}} \quad\left({ }^{\circ} \mathrm{C}\right)$ & $\xi_{\mathrm{TA}}$ & PGR (\%) & TEC (\%) \\
\hline 40 & 60 & 32.56 & 0.814 & 3.013 & +0.137 & 33.68 & 0.842 & 2.55 & +0.116 \\
\hline 40 & 40 & 27.83 & 0.696 & 5.012 & +0.223 & 29.66 & 0.742 & 4.234 & +0.190 \\
\hline 40 & 20 & 22.03 & 0.551 & 7.546 & +0.328 & 24.73 & 0.618 & 6.359 & +0.280 \\
\hline 40 & 10 & 18.57 & 0.464 & 9.102 & +0.39 & 21.79 & 0.545 & 7.658 & +0.333 \\
\hline
\end{tabular}

Table 2. The maximum PGR and TEC with different ambient air conditions and evaporative cooler effectiveness.

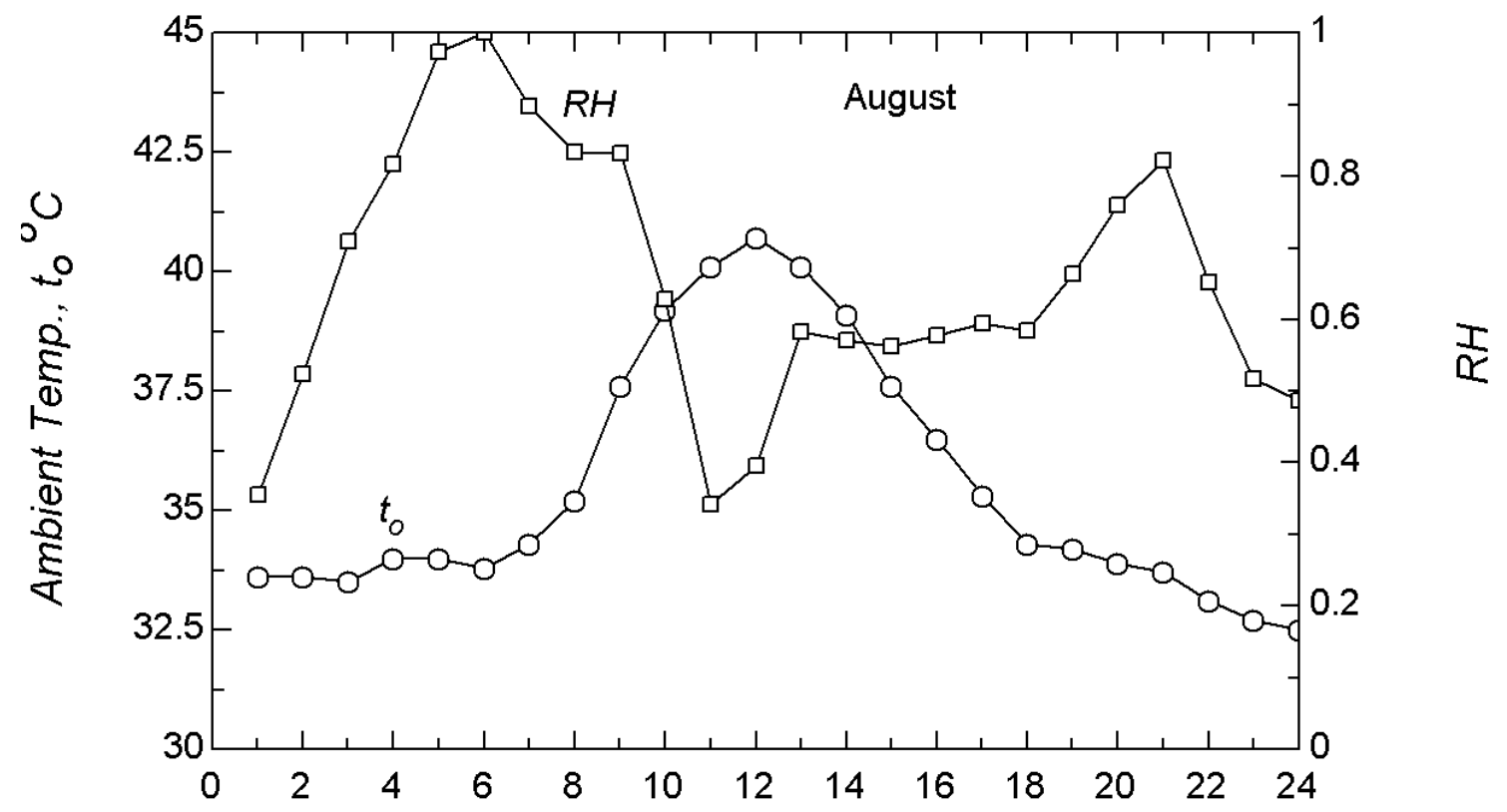

Hour duration

Fig. 10. August RH and ambient temperature variations. 


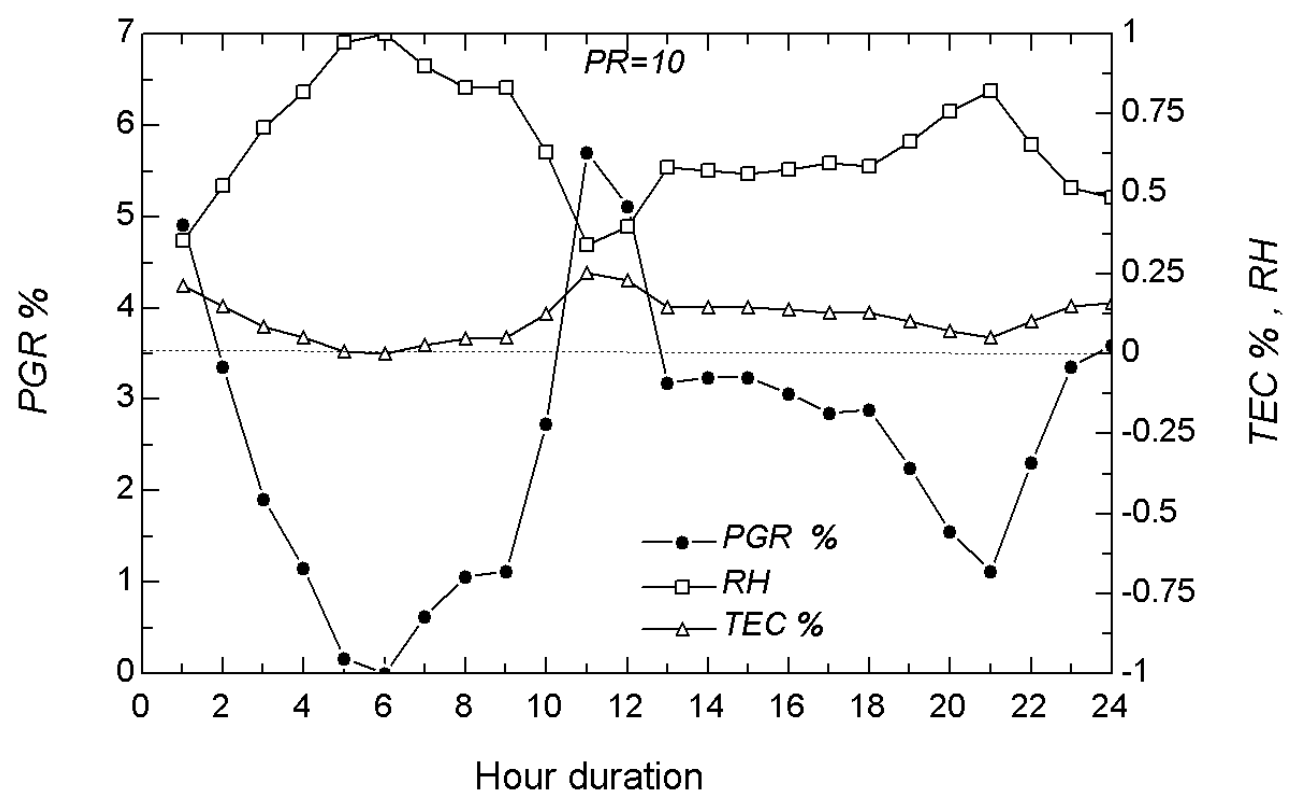

Fig. 11. Dependence of gas turbine maximum PGRon RH of direct evaporative cooler.

In order to examine the daily performance of the cooling system,we assume that this system reduces the intake air temperature from $\mathrm{T} 0$ to $\mathrm{T} 1$, for which the evaporative cooler effectiveness is $100 \%$ and it operates for 24 hours, applying Eqs. 19 and 20, on hourly basis, using the ambient data of Fig. 10. The variation of the PGR and TEC for the evaporative cooler is presented in Fig. 11. This figure shows that the PGR and TEC drop rapidly to reach zeros at $6 \mathrm{AM}$ where $\xi \mathrm{T}$ approaches 1during early morning hours with the $100 \% \mathrm{RH}$. At $11 \mathrm{AM}$ and $40.1{ }^{\circ} \mathrm{C}$ air temperature withRH of $34.1 \%$, the gain reaches $5.706 \%$ and the thermal efficiency improvement is $0.253 \%$, where the humidity is the least.

The values show that the cooling system is promising when operated under favorable conditions but the overall daily performance is what counts at the end. The practical illustrative application indicates that the evaporative system provides additional energy of $2.52 \%$.

\section{Conclusions}

The effect of inlet air cooling on the performance of a simple gas turbine plant is investigated. Systematic analysis of a GT cycle coupled to a cooling system is presented for an evaporative air cooling process. The performance improvement showed strong dependency on the climatic conditions and evaporative cooler effectiveness and to some degree on the gas turbine pressure ratio. The evaporative cooling is quite efficient for $40^{\circ} \mathrm{C}$ dry air and $10 \% \mathrm{RH}$ ambient air. The maximum power gain and the thermal efficiency improvements are $9.102 \%$ and $0.39 \%$, respectively. The direct evaporative cooling process is limited by the wet bulb temperature at which additional water spray would not contribute any further cooling effects. The performance of the evaporative cooling is presented in a general dimensionless working graph that directly relates the maximum power gain and thermal efficiency variation to the ambient conditions.
Finally, the performance of the air cooling system was examined for the hot and humid conditions of Jeddah, Saudi Arabia. The actual climate on August 16 is selected as base data for investigation. The daily power output and the thermal efficiency improvement were only $2.52 \%$ and $0.112 \%$, respectively.

In addition, to improvethe thermal efficiency and power gaining, evaporative spray cooler improves the environmental impact of the GT, since increasing water vapor in the inlet air tends to lower the amount of nitrogen oxides (NOx) emissions as well as reduce the dust due to air washing.

\section{Acknowledgments}

This project was funded by the National Plan for Science, Technology and Innovation (MAARIFAH)-King Abdulaziz City for Science and Technology-the kingdom of Saudi Arabia-award number (8-ENE 288-03). The authors also, acknowledge with thanks Science and Technology Unit, King Abdulaziz University for technical support.

\section{Nomenclature}

$\begin{array}{ll}\mathrm{c}_{\mathrm{p}} & \text { specific heat at constant pressure }\left(\mathrm{kJ} \mathrm{kg}^{-1} \mathrm{~K}^{-1}\right) \\ \mathrm{i} & \text { specific enthalpy }\left(\mathrm{kJ} \cdot \mathrm{kg}^{-1}\right) \\ \mathrm{k} & \text { specific heats ratio } \\ \mathrm{NCV} & \text { net calorific value }=42500\left(\mathrm{~kJ} \mathrm{~kg}^{-1}\right) \\ \mathrm{P} & \text { pressure }(\mathrm{kPa}) \\ \mathrm{PR} & \text { pressure ratio }=\mathrm{P}_{2} / \mathrm{P}_{1} \\ \mathrm{PGR} & \text { power gain ratio } \\ \dot{Q}_{h} & \text { heat rate }(\mathrm{kW}) \\ \dot{m} & \text { mass flow rate }\left(\mathrm{kg} \mathrm{s}^{-1}\right) \\ \mathrm{t} & \text { temperature }{ }^{\circ} \mathrm{C} \\ \mathrm{T} & \text { absolute temperature, } \mathrm{K} \\ \mathrm{TEC} & \text { thermal efficiency change, Eq. } 20\end{array}$




\begin{tabular}{ll}
$\dot{W}$ & power, $\mathrm{kW}$ \\
Greek & symbols \\
$\eta$ & efficiency \\
$\varepsilon_{\mathrm{evc}}$ & evaporative cooler effectiveness \\
$\xi_{\mathrm{T}}$ & temperature ratio $t_{1} / t_{o}$ \\
$\xi_{\mathrm{T}}$ & actual temperature ratio $t_{\overline{1}} / t_{o}$ \\
$\mathrm{Subscripts}$ & \\
0 & ambient \\
$\mathrm{a}$ & dry air \\
$\mathrm{c}$ & compressor \\
$\mathrm{cy}$ & cycle \\
$\mathrm{e}$ & evaporator \\
evc & evaporative cooler \\
$\mathrm{f}$ & fuel \\
$\mathrm{fg}$ & latent heat \\
$\mathrm{h}$ & heat \\
rev & reversible \\
$\mathrm{t}$ & turbine \\
$\mathrm{v}$ & water vapor \\
& \\
\hline
\end{tabular}

\section{References}

[1] Zadpoor AA, Golshan AH. Performance improvement of a gas turbine cycle by using adesiccant-based evaporative cooling system. Energy 2006; 31:2652-2664.

[2] Chaker M, Homji CBM, Mee III TR. Inlet fogging of gas turbine engines. Proceedings of ASME Turbo Expo; 2001 June 4-7; New Orleans, USA; 2001.

[3] AL-Hamdan OR, Saker AA.Studying the role played by evaporative cooler on the performance of GE gas turbine existed in Shuaiba North Electric Generator Power Plant. Energy Power Eng 2013; 5:391-400.
[4] Johnson RS. The theory and operation of evaporative coolers for industrial gas turbine installations. J Eng Gas Turbines Power 1989; 111:327-334.

[5] Alhazmy MM, Najjar YSH. Augmentation of gas turbine performance using air coolers. App Therm Eng 2004; 24:415-429.

[6] Meher H, Cyrus B, Mee RT, Thomas R. Inlet fogging of gas turbine engines, part B: droplet sizing analysis nozzle types, measurement and testing. Proc ASME Turbo Exo 2002; 2002 June 3-6; Amsterdam, The Netherlands.

[7] Bettocchi R, Spina PR, Moberti F. Gas turbine inlet air cooling using non-adiabatic saturation process. ASME Cogen-Turbo Power Conf; 1995 August 23-25; Vienna, Austria .ASME; 1995.p.1-10.

[8] Cyrus B, Mee RT. Gas turbine power augmentation by fogging of inlet air. Proc 28th Turbomach Symp. 1999.p.95-114.

[9] Korakianities T, Wilson DG. Models for predicting the performance of Brayton-cycle engines.Eng Gas Turbine Power $1994 ; 116: 381-388$.

[10] Klein KA, Alvarado FL. EES-Engineering Equation Solver, F-Chart Software.Middleton, WI.

[11] Dossat RJ. Principles of refrigeration, New York: John Wiley and Sons; 1997.

[12] Cortes CPE, Willems D. Gas turbine inlet cooling techniques: an overview of current technology. Proc Power GEN 2003; 2003 Dec. 9-11;Nevada, USA.

[13] McQuiston FC, Parker JD, SpilterJD. Heating, ventilating and air conditioning: design and analysis, 5 th ed. New York: Willey; 2000 .

[14] Li KW, Priddy A P. Power plant system design. New York: John Wiley \& Sons; 1985. 